\title{
Radiation dose affected by mammographic composition and breast size: first application of a radiation dose management system for full-field digital mammography in Korean women
}

\author{
Ji Eun Baek, Bong Joo Kang*, Sung Hun Kim and Hyun Sil Lee
}

\begin{abstract}
Background: Relative to Western women, Korean women show several differences in breast-related characteristics, including higher rates of dense breasts and small breasts. We investigated how mammographic composition and breast size affect the glandular dose during full-field digital mammography (FFDM) in Korean women using a radiation dose management system.

Methods: From June 1 to June 30, 2015, 2120 FFDM images from 560 patients were acquired and mammographic breast composition and breast size were assessed. We analyzed the correlations of patient age, peak kilovoltage $(\mathrm{k} \vee \mathrm{p})$, current $(\mathrm{mAs})$, compressed breast thickness, compression force, mammographic breast composition, and mammographic breast size with the mean glandular dose (MGD) of the breast using a radiation dose management system. The causes of increased radiation were investigated, among patients with radiation doses above the diagnostic reference level (4th quartile, $\geq 75 \%$ ).

Results: The MGD per view of 2120 images was $1.81 \pm 0.70 \mathrm{mGy}$. In multivariate linear regression analysis, age was negatively associated with MGD $(p<0.05)$. The mAs, kVp, compressed breast thickness, and mammographic breast size were positively associated with MGD $(p<0.05)$. The "dense" group had a significantly higher MGD than the "non-dense" group $(p<0.05)$. Patients with radiation dose values above the diagnostic reference value had large breasts of dense composition.
\end{abstract}

Conclusions: Among Korean women, patients with large and dense breasts should be more carefully managed to ensure that a constant radiation dose is maintained.

Keywords: Radiation dose, Digital mammography, FFDM

\section{Background}

The use of imaging modalities that utilize ionizing radiation has become increasingly common. Consequently, there is growing concern about the risk of radiation exposure $[1,2]$. The cancer risk associated with radiation exposure is generally extrapolated from the long-term follow-up of Japanese atomic bomb survivors from

\footnotetext{
* Correspondence: lionmain@catholic.ac.kr

Department of Radiology, Seoul St. Mary's Hospital, College of Medicine, The

Catholic University of Korea, 222, Banpo-daero, Seocho-gu, Seoul 06591, Republic of Korea
}

Hiroshima and Nagasaki [3-6]. Regarding the radiation dose, there is a general consensus on the importance of radiation dose management for patient safety. Thus, clinicians are attempting to reduce the radiation dose for patient safety. Several software programs are available to aggregate and analyze data regarding radiation dose management. A radiation dose management system could help radiologists optimize protocols, reduce the radiation dose, and perform quality management.

With respect to mammography, it is well known that the risk of radiation-induced breast cancer is not a 
deterrent to the mammographic screening of women over 40 years of age; moreover, several studies of Western women have indicated that when woman-years of life are considered, the benefits of earlier detection are particularly pronounced [7-9]. From another perspective, there is notable concern regarding radiation doses from mammography and the risk of radiation-induced breast cancer resulting from the use of mammography for periodic screening. Women may undergo many mammograms during their lifetimes.

Relative to Western women, Korean women show several differences in breast-related characteristics, including higher rates of dense breasts and small breasts as well as a younger age of breast cancer onset [10-12]. Therefore, this cross-sectional study of Korean women was conducted to evaluate the factors correlated with radiation dose, including mammographic breast composition and mammographic breast size. Moreover, this study describes the first application of a commercial radiation dose management system (Radimetrics ${ }^{\mathrm{Tm}}$ ) for fullfield digital mammography (FFDM) in Korean women. Using this system, we collected multiple, uncomplicated measurements from patients who underwent mammography and evaluated the factors associated with increased radiation dose during FFDM in Korean women.

The purposes of the present study were to investigate how mammographic composition and breast size affected the glandular dose during full-field digital mammography (FFDM) in Korean women, to evaluate the usefulness of the implemented software (radiation dose management system) for collecting various data from mammography patients, and to determine the factors associated with increased radiation dose during FFDM in Korean women.

\section{Methods}

Our institutional review board approved this prospective study and waived the requirement for informed patient consent. We collected mammographic images acquired in June 2015 from two FFDM units [Mammomat Inspiration (Siemens; Erlangen, Germany) and Selenia (Hologic; Bedford, MA, USA)]. The Mammomat Inspiration unit was used from January 1, 2009, and the Selenia unit was used from August 1, 2006. We excluded spot compression and magnification views, mammography-guided localization images, specimen mammography images, and images of stereotactic biopsies. We also excluded images from male patients. Multiple images obtained over time for individual participants were not included in this study. Bilateral or unilateral mammography with routine craniocaudal (CC) and mediolateral oblique (MLO) views of each participant were included.

From June 1 to June 30, 2015, 2321 FFDM images were acquired and sent to PACS and the server of the radiation dose management system. After the exclusion of 201 images (which were spot compression and magnification views; generated for mammography-guided localization, specimen mammography, or stereotactic biopsy; and/or from male patients), 2120 images from 560 patients who underwent bilateral or unilateral mammography with routine CC and MLO views remained. Only these remaining images were included in our study.

All images were assessed for breast composition by two radiologists, with evaluations determined by consensus (BJE, 4 years of experience; BJK, 15 years of experience). The breast composition reported between two radiologists was approximately agreed upon (Gamma, 0.995; asymptotic standard error, 0.002; approx. $T^{\mathrm{b}}$, 62.254). In cases for which different breast compositions were chosen, the result was determined by consensus. Breast composition was visually and subjectively assessed based on the Breast Imaging Reporting and Data System (BI-RADS) criteria, which are as follows: (a) almost entirely fatty, (b) scattered areas of fibroglandular density, (c) heterogeneously dense, and (d) extremely dense. Breasts assessed as A or B were categorized as "non-dense", and breasts assessed as C or D were categorized as "dense".

Using the posterior nipple line, the mammographic size of the breast was also assessed by one radiologist (BJE, 4 years of experience). The radiologist measured the distance of a line drawn perpendicular from the nipple to the pectoralis muscle on the MLO view. We calculated the average of the bilateral values for bilateral mammograms and used only the ipsilateral value for unilateral mammograms.

We performed data collection and analysis of the mammographic data using a current radiation dose management system [Radimetrics ${ }^{\mathrm{mi}}$ Enterprise Platform (Bayer HealthCare, Whippany, NJ)]. The utilization data, parameters, and dose reports were sent to the conventional picture archiving and communication system (PACS) and the server of the radiation dose management system. The radiation dose management system extracted the mean glandular dose (MGD) value from the Digital Imaging and Communications in Medicine (DICOM) tag "Organ Dose (0040, 0316)", as defined in the DICOM Standard, and presented it to the application for data aggregation for analysis. The radiation dose management system showed the MGD per laterality (left or right) of the breast according to the "L" or "R" value in the image level DICOM tag "Laterality $(0020,0062)$ " and summed the MGD values within the same laterality. No other calculation was performed in the radiation dose management system. Data regarding peak kilovoltage $(\mathrm{kVp})$, current $(\mathrm{mAs})$, compressed breast thickness, and breast compression force were also extracted from the DICOM tags of each image and used for analysis. We reviewed the data using our 
personal computers by accessing the web server of the radiation dose management system.

In addition, we investigated the history of breastconserving surgery of the patients.

We analyzed the correlations of age at mammography and mammographic parameters, such as $\mathrm{kVp}$, mAs, compressed breast thickness, mammographic breast size, and breast compression force, with the MGD of the breast using univariate and multivariate linear regression analyses. We also determined the relationship between mammographic breast composition and MGD.

We divided the mammographic images into two groups as follows: images with doses above the diagnostic reference level (4th quartile, $\geq 75 \%$ ) for the MGD and images with doses below the diagnostic reference level (1st to 3rd quartile, $<75 \%$ ) for the MGD. We used the MGD values of mammograms conducted during June 2015 at our hospital to determine this diagnostic reference level. Additionally, we investigated whether factors such as age, mammographic parameters $(\mathrm{kVp}, \mathrm{mAs}$, compressed breast thickness, mammographic breast size and breast compression force), and mammographic breast composition were significantly correlated with doses above the diagnostic reference level (4th quartile, $\geq 75 \%$ ). We analyzed the data using univariate and multivariate logistic regression analyses and independent Student's $t$ tests. All statistical analyses were performed using the software package SAS Enterprise Guide 5.1 (SAS Institute, Inc., Cary, NC) or $\mathrm{R}$ software version 2.15.3 (R Foundation for Statistical Computing, Vienna, Austria; www.r-project.org).

\section{Results}

From June 1 to June 30, 2015, 2120 consecutive images from 560 patients who underwent bilateral or unilateral mammography with routine CC and MLO views were included. The mean age of the 560 patients at mammography was 52.3 years. The mean mammographic size of the breast per person was $82.01 \mathrm{~mm}$. When the $560 \mathrm{pa}-$ tients were stratified according to mammographic breast composition, 183 patients were included in the "nondense" group (32.68\%), and 377 patients were included in the "dense" group (67.32\%). Among the 2120 included images, 260 were obtained from patients with a history of ipsilateral breast-conserving surgery (12.26\%). The average MGD per view was $1.81 \mathrm{mGy}$ (Table 1).

In univariate and multivariate linear regression analyses, age was negatively associated with MGD per view. In contrast, the mammographic breast size, mAs, compressed breast thickness, and breast compression force were positively associated with the MGD per view. According to the mammographic breast composition, the "dense" group had a significantly higher MGD than the "non-dense" group (Table 2, Figs. 1, 2, 3, and 4). The average MGD per view in the "non-dense" and "dense" groups was 1.49 and $1.96 \mathrm{mGy}$, respectively.

Among the 528 images with doses above the diagnostic reference level, the average MGD was $2.76 \mathrm{mGy}$. Among the 1592 images with doses below the diagnostic reference level, the average MGD was 1.49 mGy. The mean patient age was younger for images with doses above the diagnostic reference level compared with those below (48.19 vs. 53.17 years, respectively; $p<$ $0.0001)$. The average mammographic breast size was larger in images with doses above the diagnostic reference level compared with those below (84.94 vs. $79.71 \mathrm{~mm}$, respectively; $p<0.0001$ ). Images with doses above the diagnostic reference level were more frequently included in the "dense" group of breast composition than were images with doses below the diagnostic reference level (89.77 vs. $59.99 \%$, respectively; $p<0.0001$ ). Patients who had doses above the diagnostic reference level more commonly had a history of ipsilateral breast-conserving surgery than did patients who had doses below the diagnostic reference level (18.53 vs. $10.18 \%$, respectively; $p<$ 0.0001) (Table 3, Figs. 5 and 6).

\section{Discussion}

To our knowledge, this is the first study to report the utilization of a radiation dose management system for

Table 1 Patient characteristics

\begin{tabular}{|c|c|c|c|}
\hline \multicolumn{2}{|l|}{ Person $(n=560)$} & \multicolumn{2}{|l|}{ View $($ number $=2120)$} \\
\hline Age (years) & $52.30 \pm 10.72$ & Breast-conserving surgery & \\
\hline Mammographic breast size (mm) & $82.01 \pm 22.22$ & No & $1860(87.78 \%)$ \\
\hline Mammographic breast composition & & Yes & $260(12.26 \%)$ \\
\hline Non-dense & $183(32.68 \%)$ & Peak kilovoltage (kVp) & $28.25 \pm 1.87$ \\
\hline Dense & $377(67.32 \%)$ & Current (mAs) & $98.87 \pm 31.86$ \\
\hline Sum of MGD (mGy) & $6.85 \pm 2.90$ & Compressed breast thickness ( $\mathrm{mm}$ ) & $47.94 \pm 12.17$ \\
\hline Lorad Selenia $(n=340)$ & $7.97 \pm 2.79$ & Breast compression force $(\mathrm{N})$ & $97.51 \pm 28.35$ \\
\hline Mammomat Inspiration $(n=220)$ & $5.12 \pm 2.02$ & MGD (mGy) & $1.81 \pm 0.70$ \\
\hline
\end{tabular}

Values are given as numbers (\%) for categorical variables or means \pm standard deviations (ranges) for continuous variables $M G D$ mean glandular dose 
Table 2 Univariate and multivariate linear regression results of the mean glandular dose per view

\begin{tabular}{|c|c|c|c|c|c|c|}
\hline & \multicolumn{3}{|c|}{ Univariate linear regression } & \multicolumn{3}{|c|}{ Multivariate linear regression } \\
\hline & Beta (SE) & $p$ value & $R^{2}$ & Beta (SE) & $p$ value & Adjusted $R^{2}$ \\
\hline Age (years) & $-0.013(0.001)$ & $<0.0001$ & 0.038 & $-0.002(0.001)$ & 0.0358 & 0.820 \\
\hline Mammographic breast size (mm) & $0.004(0.001)$ & $<0.0001$ & 0.016 & $0.002(0.0004)$ & $<0.0001$ & \\
\hline \multicolumn{7}{|l|}{ Mammographic breast composition } \\
\hline Non-dense & Reference & & 0.094 & Reference & & \\
\hline Dense & $0.462(0.031)$ & $<0.0001$ & & $0.201(0.017)$ & $<0.0001$ & \\
\hline \multicolumn{7}{|l|}{ Breast-conserving surgery } \\
\hline No & Reference & & & Reference & & \\
\hline Yes & $0.249(0.046)$ & $<0.0001$ & 0.014 & $0.038(0.020)$ & 0.0605 & \\
\hline Peak kilovoltage (kVp) & $0.074(0.008)$ & $<0.0001$ & 0.039 & & & \\
\hline Current (mAs) & $0.014(0.0004)$ & $<0.0001$ & 0.384 & $0.014(0.0002)$ & $<0.0001$ & \\
\hline Compressed breast thickness (mm) & $0.013(0.001)$ & $<0.0001$ & 0.053 & $0.008(0.001)$ & $<0.0001$ & \\
\hline Breast compression force $(\mathrm{N})$ & $0.006(0.001)$ & $<0.0001$ & 0.058 & $0.003(0.0003)$ & $<0.0001$ & \\
\hline
\end{tabular}

Beta represents the unstandardized regression coefficient. Due to the high multicollinearity of $k \mathrm{p}$ with several thicknesses, we removed kVp from the multivariate linear regression analysis

SE standard error

FFDM in Korean women. Relative to Western women, these women exhibit several differences in breast-related characteristics, including higher rates of dense breasts and small breasts as well as a younger age of breast cancer onset [10-12]. Therefore, the results of this customized study for Korean women provide insight into the factors correlated with the radiation dose, including mammographic breast composition and mammographic breast size. Moreover, the present study describes the present authors' experience with a commercial radiation dose management system (Radimetrics ${ }^{\mathrm{Tx}}$ ) for FFDM.
Using this system, we easily collected the MGD values of patients who underwent mammography and analyzed the factors affecting MGD.

In our study, the average MGD per view was $1.81 \mathrm{mGy}$. This value is similar to values from the American College of Radiology Imaging Network (ACRIN) Digital Mammographic Imaging Screening Trial (DMIST) [7]. Hendrick et al. [13] reviewed the dose data of a large population in ACRIN DMIST and reported an average MGD of $4.7 \mathrm{mGy}$ from two-view screen film mammography and $3.7 \mathrm{mGy}$ from two-view

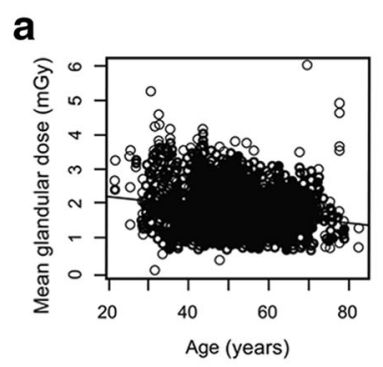

d

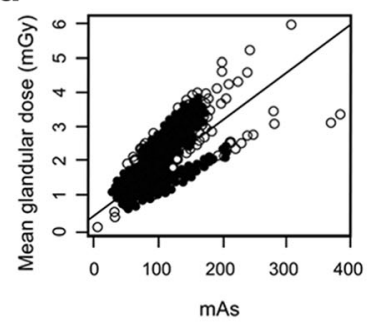

b

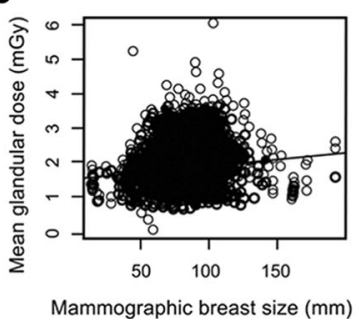

e

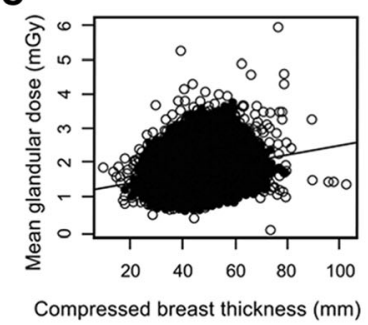

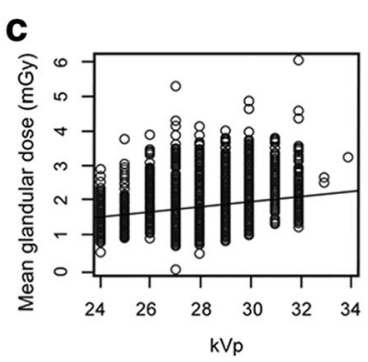

f

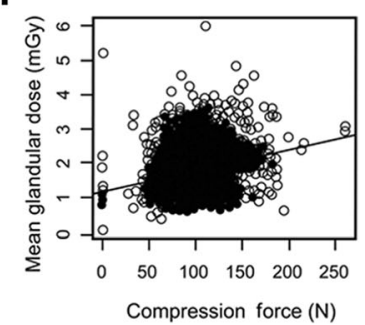

Fig. 1 a Scatterplot showing a negative correlation between age and MGD. b-f Scatterplots showing positive correlations between MGD and each of mammographic breast size, kVp, mAs, compressed breast thickness, and compression force 


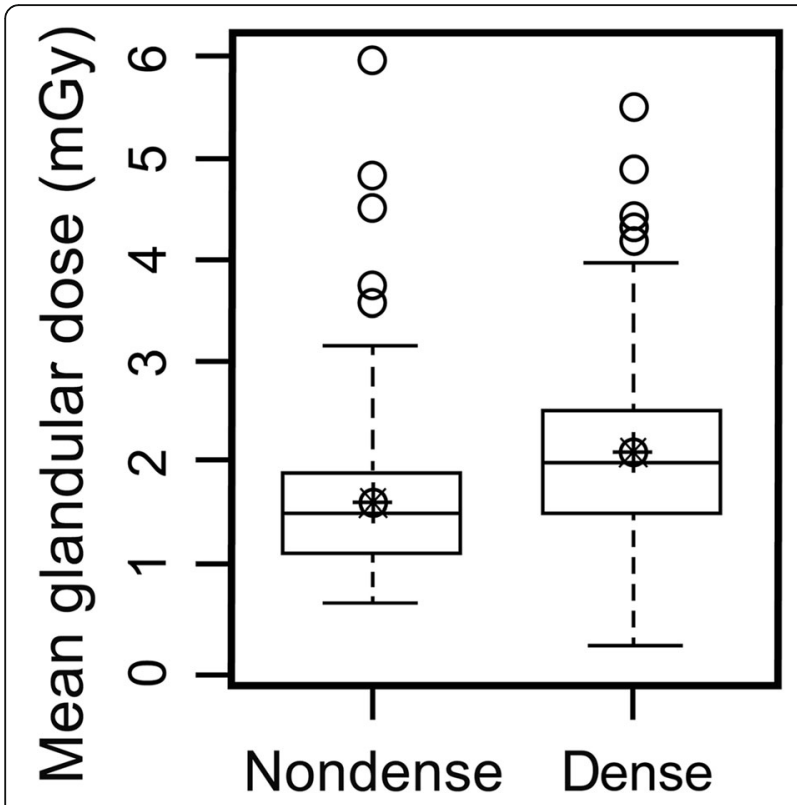

Fig. 2 Box-and-whisker plots showing higher MGD in the "dense" group than in the "non-dense" group (1.96 vs. 1.49 mGy)

digital mammography. When these MGDs are adjusted by the International Commission on Radiological Protection (ICRP) tissue-weighting factor $(0.12$ for breast tissue), an average effective dose of 0.56 and $0.44 \mathrm{mSv}$ are obtained [14]. In our study, the average MGD from twoview mammography was approximately $3.62 \mathrm{mGy}$, which is twice the average MGD from a single view. The average effective dose in our study was $0.43 \mathrm{mSv}$. This result can be compared to the average effective dose from natural background radiation (3 $\mathrm{mSv}$ per year) [15]. In 2007, the ICRP reported that the lifetime attributable risk (LAR) for fatal cancer induction in adults was $4.1 \%$ per Sievert [14].
The United States National Academy of Sciences Biologic Effects of Ionizing Radiation (BEIR) VII Group has reported the estimated age-dependent risks of radiationinduced cancer incidence and mortality [3]. Using these BEIR VII estimates, Hendrick [7] reported the agedependent LAR for two-view mammography with an MGD of 3.7 to $4.7 \mathrm{mGy}$. For example, the LAR for breast cancer incidence in a 40-year-old woman who has undergone two-view mammography of both breasts is five to seven cases per 100,000 . The LAR of a 20 -yearold woman is $16-20$ cases per 100,000 . The LAR of an 80 -year-old woman is $0.1-0.2$ cases per 100,000 . According to this report, even with the same mammographic radiation doses, younger women have a greater risk of developing breast cancer. Furthermore, in our study, young age was significantly associated with high MGD $(p=0.0358)$. Younger women generally have denser breasts and may require higher MGDs. Thus, young age is related to an increased risk of radiation-induced cancer and mortality and is also related to high MGDs. Therefore, better radiation dose management is clearly required for all women, with careful dose management a particularly important consideration for young women undergoing mammography.

The present study also provides insight into the factors that may affect radiation dose. Two major factors that affect radiation dose are the amount of compression and the thickness of the breast [16-19]. In addition to these factors, we assessed mammographic composition and breast size of Korean women. Mammographic breast composition is important for the following reasons. First, dense composition may obscure lesions and lower the mammographic sensitivity. Second, increased mammographic breast composition is a significant risk factor for developing breast cancer [20, 21]. In this study, high MGD was associated with "dense" mammographic

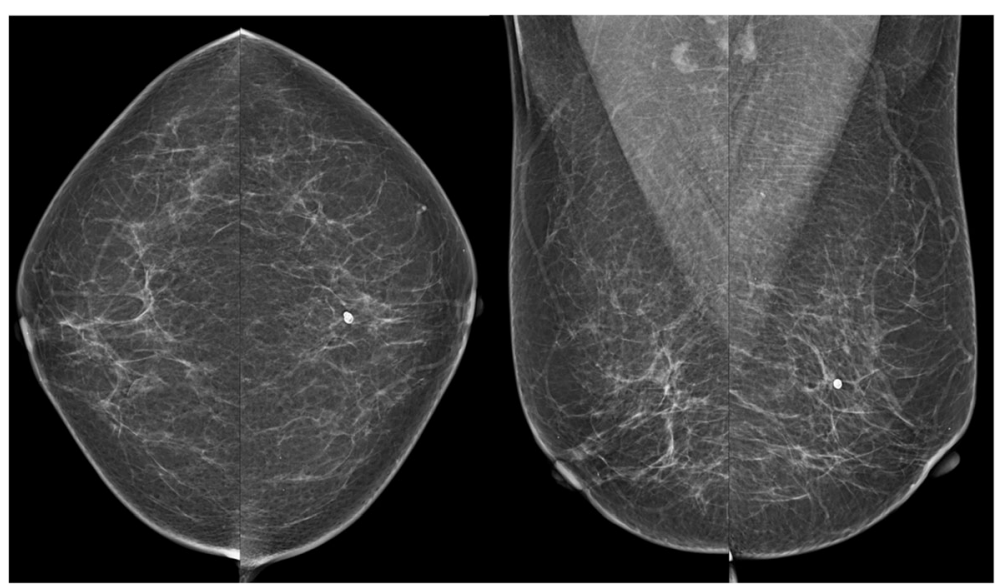

Fig. 3 A 62-year-old woman with "non-dense" breast composition and small breasts (mean mammographic breast size, $74.13 \mathrm{~mm}$ ). The average MGD per view was $1.10 \mathrm{mGy}$ 


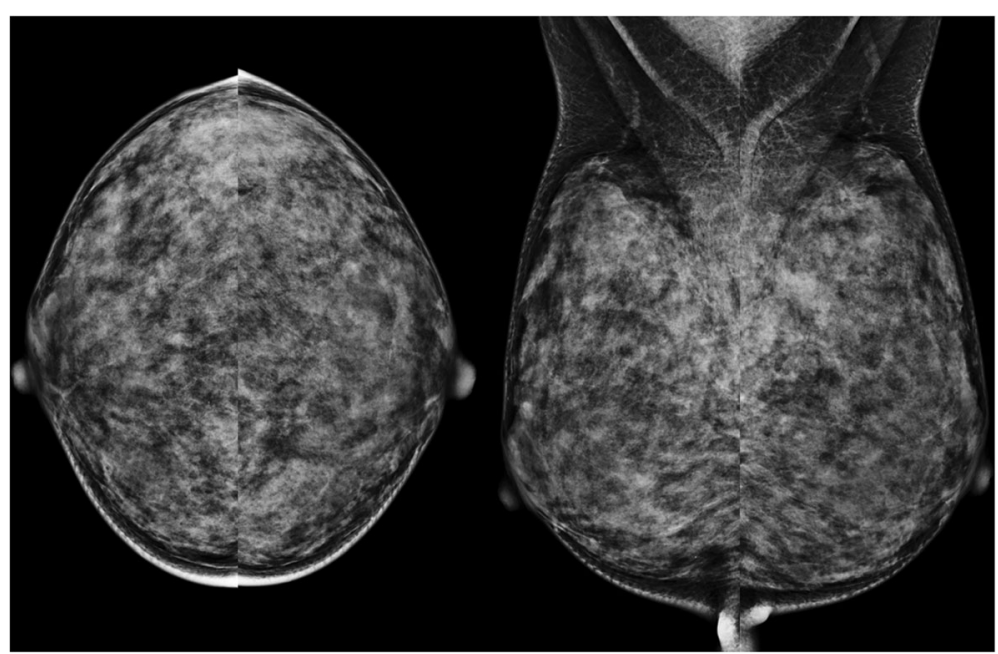

Fig. 4 A 41-year-old woman with "dense" breast composition and large breasts (mean mammographic breast size, 83.74 mm). The average MGD per view was $2.38 \mathrm{mGy}$

breast composition. Ozdemir et al. [22] reported similar results. More radiation penetration is required for dense glandular tissue than for fatty breast tissue. In Korean women, the proportion of "dense" mammographic breast composition based on radiologist estimates and automated volumetric density measurements is $61.9-86.4 \%$ (vs. "non-dense", 13.6-38.2\%) [10, 20, 23, 24], whereas in Western women, the corresponding proportion is $36.9-51 \%$ (vs. "non-dense", 49.1-63.2\%) [25, 26]. Patients with larger breasts have significantly higher MGDs during mammography. In Korean women, the mean total breast tissue volume according to automated volumetric density measurements is $380.9-466.4 \mathrm{~mL}$ $[10,20,23,24]$, whereas the corresponding mean among Western women is $551.95-774 \mathrm{~mL}[26,27]$. However, in this present study, mammographic breast size was measured from the MLO view. The mean was $82.01 \mathrm{~mm}$, which might be smaller than that of Western women. The linear positive relationship between compressed breast thickness and MGD is well known, and our results are similar to those of prior studies [16-19]. The correlations between mAs and MGD in our study can be explained by the linear increase in dose with $\mathrm{mAs}$, which is related to beam quantity [28].

Table 3 Group characteristics according to the mean glandular dose (75th percentile)

\begin{tabular}{|c|c|c|c|}
\hline & $<$ MGD 75th percentile & 2MGD 75th percentile & $p$ value \\
\hline View $(n=2120)$ & $1592(75.06 \%)$ & $528(24.9 \%)$ & \\
\hline Mean glandular dose (mGy) & $1.49 \pm 0.43(0.04-2.28)$ & $2.76 \pm 0.47(2.18-5.97)$ & \\
\hline Age (years) & $53.17 \pm 10.44$ & $48.19 \pm 10.83$ & $<0.0001$ \\
\hline Mammographic breast size (mm) & $79.71 \pm 23.45$ & $84.94 \pm 19.64$ & $<0.0001$ \\
\hline \multicolumn{4}{|l|}{ Mammographic breast composition } \\
\hline Non-dense & $637(40.01 \%)$ & $54(10.21 \%)$ & \multirow[t]{2}{*}{$<0.0001$} \\
\hline Dense & 955 (59.99\%) & $474(89.77 \%)$ & \\
\hline \multicolumn{4}{|l|}{ Breast-conserving surgery } \\
\hline No & $1430(89.82 \%)$ & $430(81.44 \%)$ & \multirow[t]{2}{*}{$<0.0001$} \\
\hline Yes & $162(10.18 \%)$ & $98(18.53 \%)$ & \\
\hline Peak kilovoltage (kVp) & $28.09 \pm 1.83$ & $28.73 \pm 1.91$ & $<0.0001$ \\
\hline Current (mAs) & $89.60 \pm 24.69$ & $126.77 \pm 34.65$ & $<0.0001$ \\
\hline Compressed breast thickness (mm) & $46.86 \pm 12.36$ & $51.18 \pm 10.98$ & $<0.0001$ \\
\hline Breast compression force $(\mathrm{N})$ & $94.52 \pm 27.06$ & $106.51 \pm 30.20$ & $<0.0001$ \\
\hline
\end{tabular}

Values are given as numbers (\%) for categorical variables or means \pm standard deviations (ranges) for continuous variables. $p$ values were calculated using independent Student's $t$ tests $M G D$ mean glandular dose 

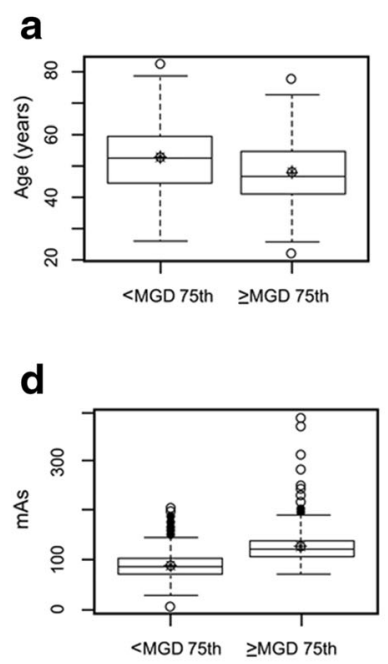
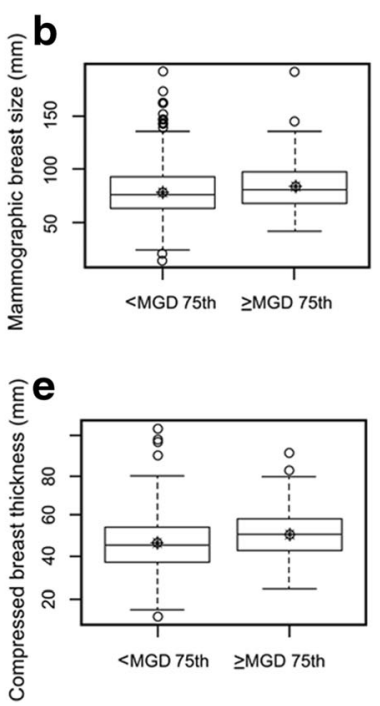

\section{C}

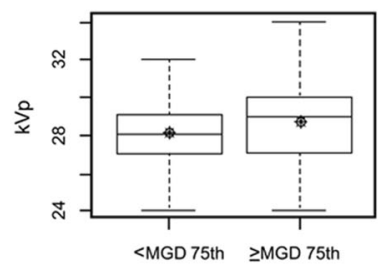

f

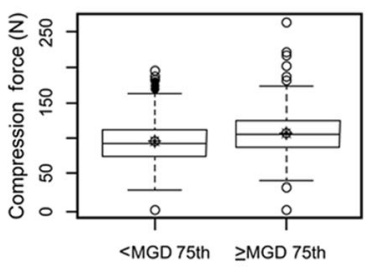

Fig. 5 a-f Box-and-whisker plots showing that doses above the diagnostic reference level are associated with young age, large mammographic breast size, high kVp, high $\mathrm{mAs}$, and increased breast thickness

Furthermore, patients who had undergone breastconserving surgery required high MGD values. We assume that the postoperative changes, including seroma, hematoma, and surgical clips, cause increased density during ipsilateral mammography.

In a previous study that did not include a radiation dose management system, the identified data were submitted to a medical physicist for data cleaning. The resulting final dataset subjected to analysis predominantly consisted of cases ( $80 \%$ of cases in the dataset) for which technical data were collected [13]. In the present study, although only one institution and two machines were included, there was no data error or data loss. Furthermore, no medical physicist was required for data cleaning.

Our study had several limitations. First, this study included mammographic images from only two manufacturers of one institution, possibly causing patient selection bias. To avoid selection bias, we analyzed the entire data including that for each manufacturer, which could also be a limitation. Second, because of a large number of factors, we did not analyze correlations or all

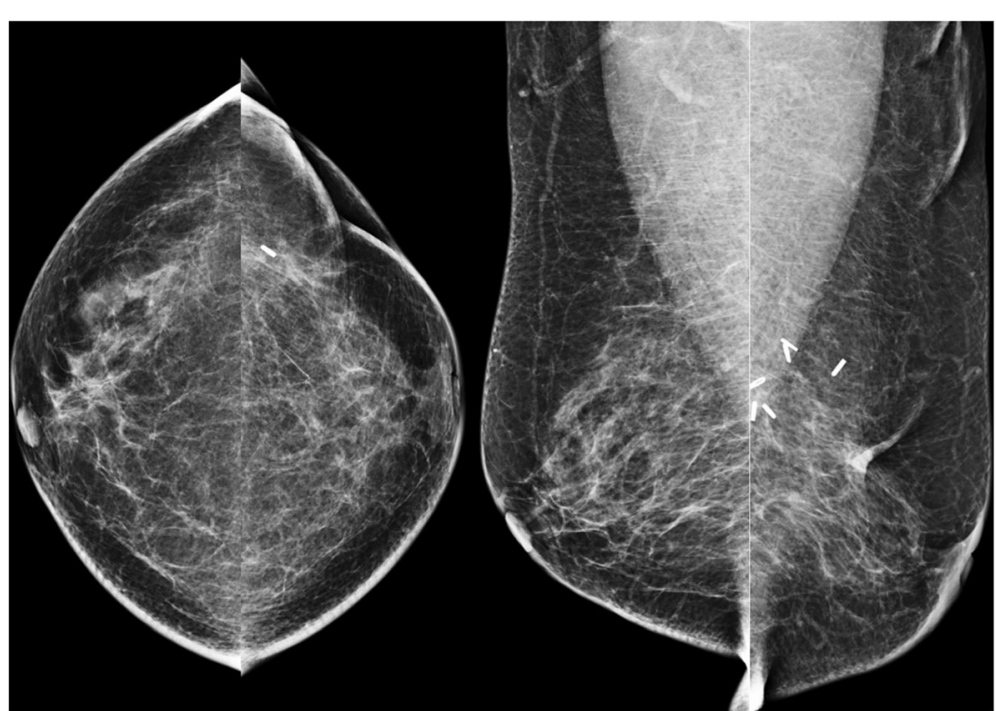

Fig. 6 A 69-year-old woman with "non-dense" breast composition, small breasts (mean mammographic breast size, 79.1 mm) and a history of left-sided breast-conserving surgery. The average MGD per view was 1.96 mGy (a higher MGD was observed on the left than on the right side). Left-side average MGD per view, 2.18 mGy; right-side MGD per view, 1.79 mGy 
factors. Due to the high multicollinearity of $\mathrm{kVp}$ with several thicknesses, we removed $\mathrm{kVp}$ as a variable from the multivariate linear regression analyses. There was an inverse association with increased age, which was statistically significant according to univariate analysis but marginally significant after adjusting for other covariates. Our results suggest that breast size and composition are other covariates associated with age; however, further analysis will be needed to confirm this. In addition, we did not analyze other important confounders such as body mass index, and we only analyzed the breast size and thickness. It would be interesting to follow up this study with a larger number of institutions and manufacturers, a correlation analysis, and an examination of confounders.

In centers with good quality control and well-managed devices, such as our center, the radiation dose is not high. Quality control and device management are very important in patient care, and centers and hospitals that use mammography should always endeavor to minimize the radiation dose as much as possible. Furthermore, because mammography is performed only annually or biannually, summation and monitoring with other modalities is needed in future studies.

\section{Conclusions}

Among Korean women, patients with large and dense breasts should be more carefully managed to ensure that a constant radiation dose is maintained. In addition, we should devote particular attention to younger women and patients who have previously undergone breastconserving surgery. Moreover, a radiation dose management system was useful during FFDM for collecting data and for analyzing factors associated with the radiation dose. We also expect that the radiation dose management system could help control the radiation dose during FFDM.

\section{Abbreviations \\ ACRIN: American College of Radiology Imaging Network; BEIR: Biologic Effects of Ionizing Radiation; CC view: Craniocaudal view; DICOM: Digital Imaging and Communications in Medicine; DMIST: Digital Mammographic Imaging Screening Trial; FFDM: Full-field digital mammography; ICRP: International Commission on Radiological Protection; LAR: Lifetime attributable risk; MGD: Mean glandular dose; MLO view: Mediolateral oblique view; PACS: Conventional picture archiving and communication system}

\section{Acknowledgements}

Statistical consultation was supported by the Catholic Research Coordinating Center of the Korea Health 21 R\&D Project (A070001), Ministry of Health and Welfare, Republic of Korea.

\section{Funding}

The authors declare that they have no funding sources.

Availability of data and materials

Please contact the corresponding author for request of the data.

\section{Authors' contributions}

JEB and BJK participated in the conception of the study, the data collection and analysis, and the drafting of the manuscript. SHK and HSL participated in the data collection and analysis. All authors read and approved the final manuscript.

\section{Competing interests}

The authors declare that they have no competing interests.

\section{Consent for publication}

Consent was obtained from those patients whose images are included in this manuscript.

\section{Ethics approval and consent to participate}

Our institutional review board (CMC clinical research and coordination center) approved this prospective study and waived the requirement for informed patient consent (reference number, KC15EISI0976).

Received: 6 September 2016 Accepted: 25 January 2017

Published online: 02 February 2017

\section{References}

1. Linton OW, Mettler Jr FA. National Council on Radiation Protection and Measurements: national conference on dose reduction in CT, with an emphasis on pediatric patients. AJR Am J Roentgenol. 2003;181:321-9.

2. Brenner DJ, Elliston CD, Hall EJ, Berdon WE. Estimates of the cancer risks from pediatric $\mathrm{CT}$ radiation are not merely theoretical: comment on "point/ counterpoint: in $\mathrm{x}$-ray computed tomography, technique factors should be selected appropriate to patient size. against the proposition". Med Phys. 2001;28:2387-8.

3. National Research Council (US) Committee to Assess Health Risks from Exposure to Low Level of Ionizing Radiation. Health risks from exposure to low levels of ionizing radiation: BEIR VII phase 2. Washington: National Academies Press; 2006. p. 406.

4. Preston DL, Pierce DA, Shimizu Y, Cullings HM, Fujita S, Funamoto S, Kodama K. Effect of recent changes in atomic bomb survivor dosimetry on cancer mortality risk estimates. Radiat Res. 2004;162:377-89.

5. Preston DL, Ron E, Tokuoka S, Funamoto S, Nishi N, Soda M, Mabuchi K, Kodama K. Solid cancer incidence in atomic bomb survivors: 1958-1998. Radiat Res. 2007;168:1-64.

6. Preston DL, Shimizu Y, Pierce DA, Suyama A, Mabuchi K. Studies of mortality of atomic bomb survivors. Report 13: solid cancer and noncancer disease mortality: 1950-1997. Radiat Res. 2003;2012(178):AV146-72.

7. Hendrick RE. Radiation doses and cancer risks from breast imaging studies. Radiology. 2010;257:246-53.

8. Yaffe MJ, Mainprize JG. Risk of radiation-induced breast cancer from mammographic screening. Radiology. 2011;258:98-105.

9. Hauge $\mathrm{IH}$, Pedersen $\mathrm{K}$, Olerud $\mathrm{HM}$, Hole EO, Hofvind $\mathrm{S}$. The risk of radiationinduced breast cancers due to biennial mammographic screening in women aged 50-69 years is minimal. Acta Radiol. 2014;55:1174-9.

10. Ko SY, Kim EK, Kim MJ, Moon HJ. Mammographic density estimation with automated volumetric breast density measurement. Korean J Radiol. 2014; 15:313-21.

11. Kang BJ, Kim SH, Choi BG. Comparison of full-field digital mammography workstation and conventional picture archiving and communication system in image quality and diagnostic performance. Clin Imaging. 2011;35:336-40.

12. Crystal P, Strano SD, Shcharynski S, Koretz MJ. Using sonography to screen women with mammographically dense breasts. AJR Am J Roentgenol. 2003; 181:177-82.

13. Hendrick RE, Pisano ED, Averbukh A, Moran C, Berns EA, Yaffe MJ, Herman B, Acharyya S, Gatsonis C. Comparison of acquisition parameters and breast dose in digital mammography and screen-film mammography in the American College of Radiology Imaging Network digital mammographic imaging screening trial. AJR Am J Roentgenol. 2010;194:362-9.

14. International Commission on Radiological Protection. The 2007 Recommendations of the International Commission on Radiological Protection. ICRP publication 103. Ann ICRP. 2007;37:1-332.

15. National Council on Radiation Protection and Measurements. Report no. 160-ionizing radiation exposure of the population of the United States (2009). Bethesda: National Council on Radiation Protection and Measurements; 2009. p. xv-387. 
16. Bor D, Tukel S, Olgar T, Aydin E. Variations in breast doses for an automatic mammography unit. Diagn Interv Radiol. 2008;14:122-6.

17. Gentry JR, DeWerd LA. TLD measurements of in vivo mammographic exposures and the calculated mean glandular dose across the United States. Med Phys. 1996;23:899-903.

18. Kruger RL, Schueler BA. A survey of clinical factors and patient dose in mammography. Med Phys. 2001;28:1449-54.

19. Moran P, Chevalier M, Ten JI, Fernandez Soto JM, Vano E. A survey of patient dose and clinical factors in a full-field digital mammography system. Radiat Prot Dosimetry. 2005;114:375-9.

20. Seo JM, Ko ES, Han B-K, Ko EY, Shin JH, Hahn SY. Automated volumetric breast density estimation: a comparison with visual assessment. Clin Radiol. 2013;68:690-5.

21. McCormack VA, dos Santos Silva I. Breast density and parenchymal patterns as markers of breast cancer risk: a meta-analysis. Cancer Epidemiol Biomark Prev. 2006;15:1159-69.

22. Ozdemir A. Clinical evaluation of breast dose and the factors affecting breast dose in screen-film mammography. Diagn Interv Radiol. 2007;13:134-9.

23. Lee HN, Sohn Y-M, Han KH. Comparison of mammographic density estimation by Volpara software with radiologists' visual assessment: analysis of clinical-radiologic factors affecting discrepancy between them. Acta Radiol. 2014:56:1061-8.

24. Gweon HM, Youk JH, Kim J-A, Son EJ. Radiologist assessment of breast density by BI-RADS categories versus fully automated volumetric assessment. Am J Roentgenol. 2013;201:692-7.

25. Brandt K, Scott C, Ma L, Mahmoudzadeh A, Jensen M, Whaley D, Wu F, Malkov S, Hruska C, Norman A, Heine J, Shepherd J, Pankratz VS, Kerlikowske $\mathrm{K}$, Vachon C. Comparison of clinical and automated breast density measurements: implications for risk prediction and supplemental screening. Radiology. 2016;279:710-9.

26. van der Waal D, den Heeten G, Pijnappel R, Schuur K, Timmers JMH, Verbeek ALM, Broeders MJM. Comparing visually assessed BI-RADS breast density and automated volumetric breast density software: a cross-sectional study in a breast cancer screening setting. PLoS One. 2015;10:e0136667.

27. Gubern-Mérida A, Kallenberg M, Platel B, Mann RM, Martí R, Karssemeijer N. Volumetric breast density estimation from full-field digital mammograms: a validation study. PLoS One. 2014:9:e85952.

28. Hatziioannou KA, Psarrakos K, Molyvda-Athanasopoulou E, Kitis G, Papanastassiou E, Sofroniadis I, Kimoundri O. Dosimetric considerations in mammography. Eur Radiol. 2000;10:1193-6.

\section{Submit your next manuscript to BioMed Central and we will help you at every step:}

- We accept pre-submission inquiries

- Our selector tool helps you to find the most relevant journal

- We provide round the clock customer support

- Convenient online submission

- Thorough peer review

- Inclusion in PubMed and all major indexing services

- Maximum visibility for your research

Submit your manuscript at www.biomedcentral.com/submit

\section{O BioMed Central}

